often lose them if they receive consideration and a sufficient convalescence. Where symptoms are of long standing, and where considerable tachycardia persists, the prognosis as to improvement is poor, especially in men intent on being discharged from the Army and therefore disposed to nurse any malady instead of combating it. Those with any long persistence of left mammary pain are unpromising. The more the nervous and psychic symptoms colour the picture the more problematic is a return to full duty. Graduated drill is intended not only as a part of treatment but as a means of sorting and assessment for grading.

The first concerted research on effort syndrome (D.A.H.), at Hampstead in 1916, was conducted on the most "typical" cases available, and the inferences therefrom as to prognosis are inapplicable to the majority. Later in the war prognosis improved, especially among men treated by medical reassurance, drill, and games, and those who remained in France in convalescent depots. About $50 \%$ recovered, and most of these then remained for reasonable periods at full duty in the line.

\section{Prevention and Treatment}

Prevention.-It will be to the country's advantage if recruiting medical boards have freedom, as I believe they have, to reject or place low in category men likely to become the subjects of effort syndrome. Such would especially be those with similar symptoms in civil life, certainly if because of them they had lost much time at work and been under their doctor or had changed their occupation. Further, weaklings of poor physique unlikely to improve by training, and those obviously of a nervous make-up, can seldom reach the highest grade of service. Nor can those with a persistent high tachycardia. For war purposes a convenient term to cover these cases would be "potential effort syndrome" (or potential E.S.).

If already accepted and serving, a man at his unit showing constant incapacity for prolonged exertion may be allotted a less onerous job in which he will prove useful instead of swelling the number with effort syndrome. It is better to keep him with the unit if at all possible, avoiding this diagnosis. If he is unfitted for the lighter work, or if none is available, the sooner he is discharged the better. The difficulty is, of course, to form a right judgment when there seems to be a studied attempt to evade service by importunity of complaints, especially as shirking in this form may become contagious. Discipline as well as encouragement is required from the medical officer, and a skilful mixture may restore and reinstate the milder cases. The importance of adequate convalescence after general infections or bronchial attacks has already been mentioned.

Treatment in Hospital, Camp, or Special Centre.-Rest in bed is absurdly out of place, and medicine is anathema. Once it is clear that there is no organic disease and the condition is properly classed as effort syndrome, further close examinations are redundant and may be harmful. The period in hospital should be as short as possible, for diminished discipline demoralizes a soldier. The heart is dismissed from the mind of the medical officer and by every means from the mind of the soldier. He is clearly told that the heart-and lungs-are sound, and that he is out of condition. He is not expected to retail his complaints again, but to get into condition and a healthier frame of mind.

Psychological methods of treatment are being tried in this war. They are likely to have much the same measure of success as they have with the common functional illhealth of practice in civil life, though under war conditions and in the mass they will be placed at a disadvantage. Many men who really want to get well and to remain in the Army are likely to be helped greatly by understanding doctors and especially by those who are experienced in psychotherapy.

Graduated drill under an intelligent and co-operative instructor is needed to promote physical fitness, and is a sound method of reassurance by implication; but games are equally important, and every incentive to recover by suggestion and distraction should be employed. Failure of such treatment will be recognized in men of good will by the production of symptoms and visible signs in the course of such retraining: It is no use taking pulse rates ; undue dyspnoea, obvious distress, and abnormal exhaustion are the useful indications. It will be difficult to deal with the shirker. A capable instructor will help greatly in deciding whether further treatment is worth while in particular cases. If not, discharge or lower grading of the genuine incapable is indicated, and the sooner the better if rehabilitation in civil employment is to be accomplished. By such sorting the standard among the progressive group is maintained and encouraged. The ideal result is achieved when a man ceases to complain, willingly carries through his treatment, and acquires a healthy desire to return to and remain with his unit.

\section{CLINICAL INVESTIGATION OF SHOCK .}

\author{
ADRIAN C. KANAAR, M.D., M.R.C.P.; \\ F.R.C.S.Ed. \\ Captain, R.A.M.C.
}

Now that the battle is raging over home soil, treatment of casualties is simplified by having all the resources of long-established and well-equipped hospitals at our disposal. It is suggested that this advantage be exploited by making and preserving records of cases of shock. Analysis of such case records is a valuable form of clinical research, and a standard shock-record card would assist comparison of results from different methods of treatment. The making of such records would be within the scope of many medical officers in charge of resuscitation wards at E.M.S. and military hospitals and would be a practical supplement to the more detailed work organized by the Medical Research Council Shock Committee.

The advantages to clinical research of recording the pertinent data of cases of shock on a special card were emphasized by Brittain and Latter (1940), and the hope was expressed that a suitable standard card would be produced for use in E.M.S. hospitals. Moreover, apart altogether from research and private case notes, there is a need for some written record of the amount, speed, and time of transfusions, and the extent and rate of improvement in blood pressure and general condition, since such details assist the surgeon in deciding on the best moment to operate and when further restorative measures are required. Such a card has advantages over the case sheet, since it involves less descriptive writing and obviates omissions.

\section{The Resuscitation Records Card}

It was with these considerations in mind that the card here reproduced was planned during seven months' experience of keeping case records as $\mathrm{O} / \mathrm{C}$ Army blood transfusion team. Although work on this card was begun in October, 1939, it has not been published before, as it seemed desirable to remould it after gaining experience of its use and after receiving the help and criticism of a number of authorities. The card may still have imperfections, but it seems best to publish it now in the hope that others may wish to use it. 
A study of papers on blood and plasma transfusions shows that the value of the conclusions drawn has often been markedly limited by the small number of cases observed. In some instances (Brewer; Maizels, Oliver, and Vaughan, 1940) the numbers have been increased by pooling the results from several centres, and such a cooperative method has distinct advantages. The present card readily lends itself to organized "pooling," and it might be possible to study several thousand cases in a few months if severe air raids continue.

As co-ordination is of importance I would be glad if all who intend to utilize this card would communicate with me c/o The Royal Society of Medicine, 1, Wimpole Street, W.1 : I would welcome any suggestions which result from

\section{Resuscitation Records Card

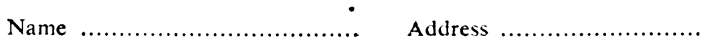 \\ Age............... Sex........... \\ Soldier's \\ No. ........... Rank ......... \\ Cause of injury \\ Lnit................................ \\ Approximate weight $\quad$......... \\ Designation of medical unit \\ ...................................... (Before ad-
mission) \\ Date \& time of admission \\ A.T.S. ......... units at ..... \\ A.G.S. \\ units at $\ldots . .$. \\ Section A. * History \\ Injuries Sustained

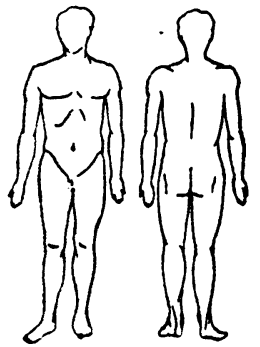

* Add brief notes, where possible, on condition and treatment before admission--e.g., dehydration, cold, pain. severe haemorrhage, sepsis (especially gas gangrene), morphine, and chemotherapy.

\section{Section C. Treatment of Shock after Admission}

1. Administration of Fluids :

(a) Intravenous

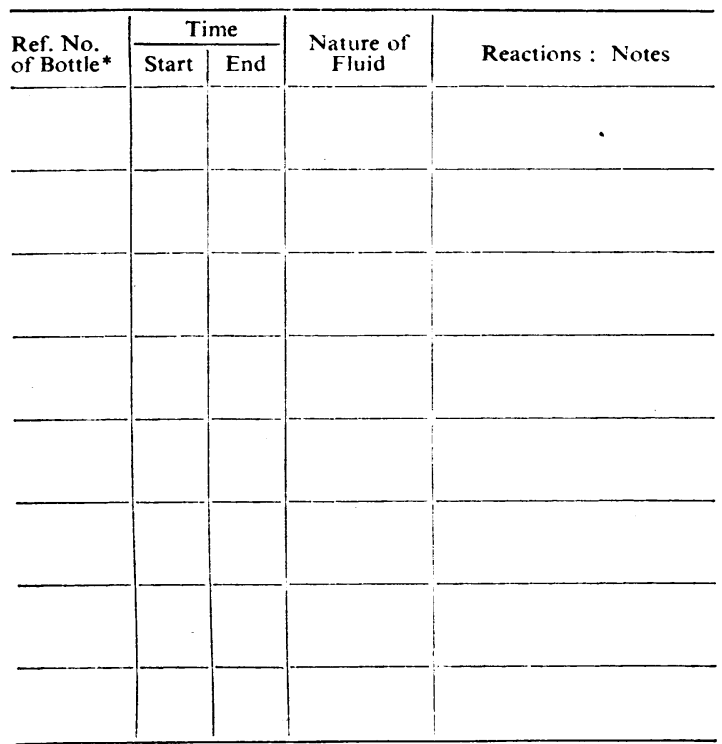

(b) Oral

(c) Rectal
Section B. Severity of Shock on Admission and during Treatment

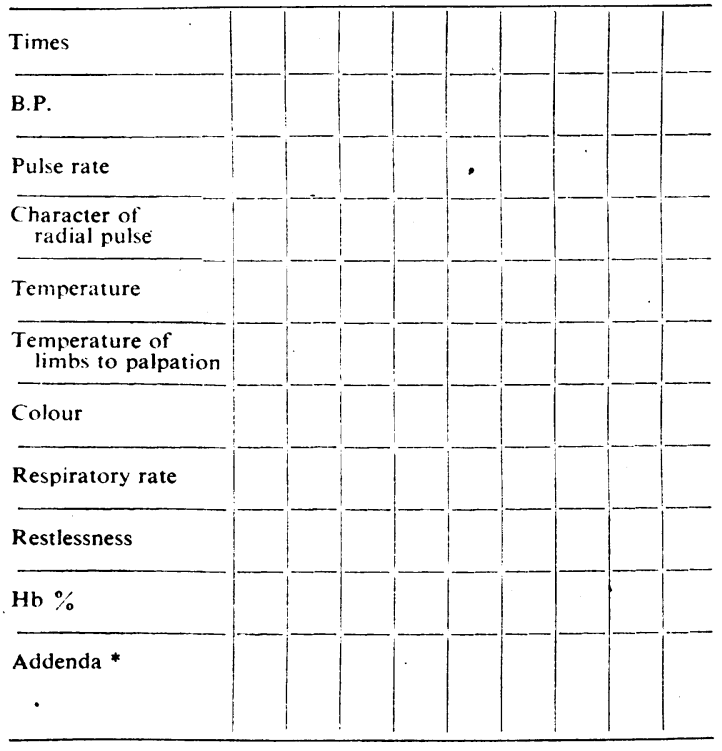

* E.g., coma, concussion, apathy, character of respiration, dryness of tongue.

Section $C$ (continued)
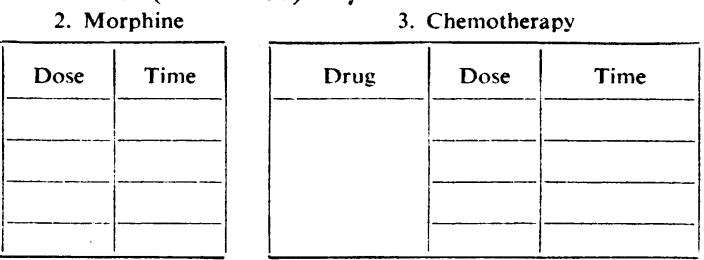

Addenda (e.g., oxygen, cortin, etc.)

Section D.

Operation

Anaesthetic.

TIME

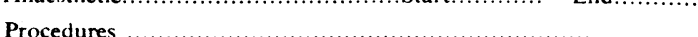

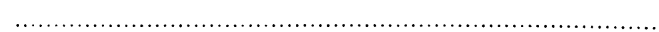

Section E. Remarks and Summary *

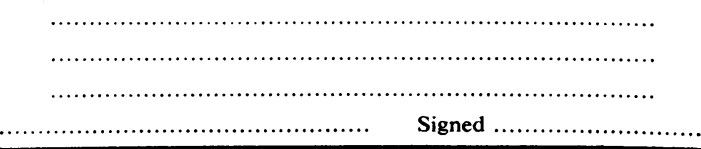

\section{Section F. Later Notes}

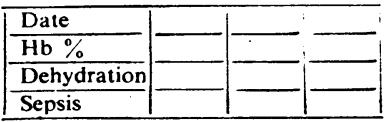

Sepsis

* E.g., factors tending to prolong shock ; summary of course and progress. 
their experience of its use. Cards may be obtained at short notice from G. E. Austin, 27, The Market Place, Richmond, Yorks ('Phone: Richmond 433), at 2s. 6d. for 20, 4s. 6d. for 50, 6s. 6d. for 100 approximately.

Some of the advantages obtained from the use of this card are :

1. The stiff cardboard facilitates writing.

2. The card is adaptable, and therefore equally useful to an ordinary resuscitation department or to a research team. For the latter purpose additional investigations such as blood volume, plasma proteins, etc., can be put in the "addenda" column.

3. The only special investigation requested is that of a series of haemoglobin estimations from a single site. These take very little time and are a useful guide to the degree of alteration in blood concentration effected by treatment. It is hoped to publish shortly a note on the interpretation of the haemoglobin percentage in relation to shock, and a copy of this could accompany the card.

4. Time is saved by diagrammatic indication of injuries and by use of a system of grouping of individual symptoms into (1) slight, (2) moderate, (3) severe, (4) very severe, the number being inserted in place of words.

\section{Description of Card}

The card is a single sheet of stiff white glazed cardboard, printed on both sides, which, folded in two, forms four pages, each 6 by $7 \frac{1}{2}$ inches. It will provide a means of assessing the value of blood, plasma, and other remedies, alone or in combination. There may be difficulty in obtaining strictly comparable cases on which to base an opinion, but this objection is more apparent than real. For example, if any combination of remedies is really better than another it should appreciably lessen the time taken to raise the systolic blood pressure to $85 \mathrm{~mm}$. $\mathrm{Hg}$ in series of cases in which it was below $60 \mathrm{~mm}$. $\mathrm{Hg}$ at the start of treatment. If a large enough' number of casese.g., several thousand-were analysed after treatment by two different methods, the other variable factors, such as degree of haemorrhage, amount of trauma and pain, duration of lesion before treatment, etc., would tend to equalize out or could be analysed separately in groups. The final test is the survival rate of severe cases.

\section{Sections $B$ and $C$}

These are described first, since they are the kernel of the investigation, and should be completed in all cases. Not every point in Section $B$ need be noted at each examination. For example, if on admission a man is pulseless, with a blood pressure of 30 and a temperature of $95^{\circ} \mathrm{F}$., there is no object in estimating his blood pressure or taking his temperature again until his pulse is palpable and his limbs are becoming warmer to palpation. One should just press on with energetic treatment, making every quarter to half an hour a brief record of any significant change in his vitality. Bloodpressure reading alone, without any other record of shock phenomena, would give a fair indication of the results of treatment.

Answers regarding severity or degree of departure from the normal should be classified into four groups. In general these are: (1) slight, (2) moderate, (3) severe, (4) very severe. These terms will apply readily to vomiting, sweating, pain. restlessness, and rigors. A similar system of groups can be employed for: (a) pulse character-(1) fair, (2) poor, (3) thready, (4) impalpable ; and (b) limb temperature-(1) slightly cool, (2) cool, (3) cold, (4) very cold. Such a classification saves much writing, and can give quite a good mental picture of the case. The skill of the observer will increase, and the individual variations of different observers will decrease, as experience of war casualties is gained. Exact details, whenever they can be given, are preferable to grouping (e.g., "Vomited 500 c.cm. at 17.00 hrs.").

Estimations of degree of shock before and after treatment are the essentials of the investigation, and these are of a reliable objective nature, provided that the blood pressure and temperature are recorded.

Estimation of Haemoglobin.--This investigation can usually be arranged in all but the busiest times. The method used should be stated. Haemoglobin estimation will reveal the extent of haemoconcentration in shock without haemorrhage (Moon, 1938), and a series of such tests are a valuable indication of progress with regard to haemorrhage and shock when under treatment (Keith, 1919; Robertson and Bock, 1919) and also during the post-operative administration of fluids (Jones and Morgan, 1938). Interpretation, however, requires some thought, since a plasma transfusion may cause a rise of haemoglobin in a case of haemorrhage (Brennan, 1940) and a blood transfusion may cause a fall. The former anomaly is apparently due to the mobilization of red blood cells which were static in the capillaries, while the latter findings are due to stimulation of the physiological response to haemorrhagenamely, withdrawal of fluid from the tissues into the blood stream.

Addenda.-Additional facts or special investigations may be noted when desired.

Continuation sheets of Section B are obtainable, and can be pinned to the card if required.

Reactions.-These refer chiefly to rigors and to sudden dyspnoea, pain in chest, cough, and collapse, with oedema of the lungs, which may result from giving intravenous fluids too quickly. Pain in the loins, bursting headache, tingling all over the body, and collapse followed after a latent period of two to seven days by anuria (Riddell, 1939) resulting from a mismatched transfusion, would also be recorded if they ever occurred. An attempt should be made to exclude inflammation as the causative factor before ascribing rigors, pyrexia, and jaundice to blood transfusion. Suspected haemoglobinuria should be confirmed by a pathologist if possible.

Fluids by Mouth and Per Rectum.-It is important to comment on the amount given, as "forced fluids" are an important factor in speeding up dilution of the blood after haemorrhage (Robertson and Bock, 1919).

Morphine and Chemotherapy.-The relief of pain and the control of infection (especially gas gangrene) have an intimate bearing upon the degree of shock, and should be carefully recorded.

Oxygen.-Details should be given of the mask used and volume of oxygen given per minute, with the duration.

Cortin, etc.-Synthetic adrenal cortical extract may be worth a trial, in view of reported results (Scudder, 1940), especially when physical exhaustion has been a contributory factor in the condition of shock. Ergotoxine is certainly deserving of trial, as shock may be due to over-stimulation of the sympathetic nervous system (McDowall, 1940).

\section{Section A}

Additional knowledge may be gained by a careful study of causative factors in cases of shock, and a note should be made of these in Section A if there is time to do so. There will be many occasions when this is impossible, but much can be accomplished by good organization and training of the transfusion personnel. An example of what can be done under war conditions was shown in January, 1940, at a meeting of a medical society in the B.E.F. in France, when a surgeon (Challenor, 1940) who had worked at a casualty clearing station in the last war produced a book in which were entered details of all his operations. These had been dictated by him to a theatre clerk towards the end of each operation. In addition M.R.C. cards were completed for many special cases, in order to trace their course after they had left the casualty clearing station.

\section{Sections D, E, and F}

Section D: Operation.-Brief details will suffice to complete the clinical picture.

Section E: Remarks and Summary.-This should be completed after a day or two, or later if possible, to indicate the ultimate outlook of the case.

Section F.-A note of the haemoglobin two to five days after the operation, in the absence of dehydration or severe infection, will give some idea of the extent of the original 
blood loss. and may he of interest in retrospect. when compared with haemoglobin readings during the phase of shock.

\section{Suggested Procedure}

(a) General duties orderly or clerk to complete details on top of page 1 for each case on admission to resuscitation wards.

(b) Nurse or trained nursing orderly to complete sections $\mathrm{A}, \mathrm{B}$, and $\mathrm{C}$ under supervision. This may be done while he is waiting for the blood or plasma to warm up and while he watches it pouring in.

(c) Resuscitation officer, (i) on admission, to take rapid history, do brief examination, and order treatment; (ii) introduce needle and collect blood for haemoglobin estimation ; (iii) later read $\mathrm{A}$ and $\mathrm{B}$ and add any further comments and notes, indicating his views of the severity of the various symptoms, signs, and complaints, and ordering further treatment; (iv) complete later notes, after two to five days if possible.

(d) Nurse or trained nursing orderly to accompany severe cases during operation, to supervise transfusion, and to complete operation and anaesthetic notes and records of blood loss at operation. Where possible the nurse or orderly who has resuscitated the case should be detailed for this work to ensure continuity of treatment and interest, but if one cannot be spared the co-operation of the anaesthetist should be invited.

\section{Summary}

The desirability of a standard record card for cases of shock in E.M.S. and military hospitals is stressed.

A resuscitation record card designed for practical utility and suitable for statistical research is described and illustrated. Copies of this card are readily obtainable.

It was from suggestions of Lieutenant (now Major) $\mathrm{H}$. W. Rodgers in January, 1940, that my blood transfusion record card was greatly improved.

My thanks are due to Major H. L. Marriott and Captain A. Kekwick for many helpful suggestions, and to Majors Hadley and Kimbell for repeated assistance in remodelling and improving the card.

Latterly I have had most useful advice from Prof. J. A. Ryle and Colonel L. E. H. Whitby, O C the Army Blood Transfusion Service, as a result of which the card has been much shortened and its objective focused on results of treatment. Finally, a number of its details have been modified on advice from Prof. T. B. Davie, Dr. H. F. Brewer, and Lieut. J. B. Hurll.

In making these acknowledgments I must, however, accept full responsibility for production of this paper.

\section{REFERENCES}

Brennan, H. J. (1940). British Medical Journal. 1. 1047

Brewer, H. F., Maizels. M. Oliver, J. O., and Vaughan. I. (1940) Ibid., 2, 48 Brittain. H. A., and Latter, K. A. (1940), Ibid.. 2, 284

Challenor, L. T. (1940), J. R.A.M.C., 75, 53

Jones, F. Avery, and Morgan, C. Naunton (1938). St. Bart's Hosp. Rep. 71, 83.

Keith, N. M. (1919). Med. Res. Cnci. Sp. Rep. Ser. No. 26, p. 36. London. McDowall, R. J. S. (1940). British Medical Journal, 1, 919.

Moon, V. H. (1938). Shock and Related Capillary Phenomena, London.

Riddell, V. H. (1939). Blood Transfusion, London.

Robertson, O. H., and Bock, A. V. (1919). Med. Res. Cncl. Sp. Rep. Ser. No.

25, p. 213 , London.
Scudder, J. (1940). Shock: Blood Studies as a Guide to Therapy, Philadelphia.

M. Schmouchkovitch (Thèse de Paris, 1940, No. 284) records twenty-one cases, in patients aged from 11 to 53 , indicating the importance of inherited or acquired syphilis in the causation of appendicitis. Clinically there are symptoms of appendicitis-tenderness at McBurney's point and muscular resistance-which yield to anti-syphilitic treatment. Anatomically there may be a characteristic diffuse lymphocytic infiltration in the appendix, a sclero-gummatous process destroying the whole organ, gummatous ulceration of the wall of the appendix, or a plasmocytic granuloma, which is the last stage of a gumma which has perforated the muscular wall of the appendix. Lastly, the Treponema pallidum has been found in the appendix.

\section{SARCOIDOSIS}

\section{SOME SPECULATIONS AS TO THE STAGES OF INFECTION IN GENERAL}

\author{
BY
}

\section{G. ERIC LEWIS, M.A., M.B., M.R.C.P.}

Honorary Physician to the Hull Royal Infirmary and the Scunthorpe and District War Memorial Hospital

Considerable attention has recently been devoted to the condition described as the "sarcoidosis of Boeck." This paper gives details of an unusual case in which there were signs and symptoms suggestive of a "visceralization" in the central nervous system, producing the clinical syndrome known by the name of Adie.

The mere report of an unusual case is scarcely novel, but it appears that a consideration of the pathology and possible aetiology of the sarcoidosis of Boeck may well lead to an understanding of the mechanism of infection and immunity in general. Some discussion of these possibilities is attempted after a description of the particular patient.

\section{Case Record}

Mrs. A. provided a diagnostic problem lasting for nearly two years from November, 1936. She was 53 years of age when she was referred to my clinic at the Hull Royal Infirmary in that month. She had for three months past been complaining of a "blurred patch" in the lower part of the field of vision of the left eye. Apart from occasional pains in her hips and back, she presented no other symptoms of any sort. A past history of so-called "muscular rheumatism" ten years ago was elicited, but she denied any other indispositions. On examination the pupils were found to be inactive-there being no response either to light or to accommodation-and she seemed to have a tendency to Rombergism. There was, however, no sensory loss to pinprick, postural change. or vibration. The grip of both hands was firm, strong. and equal, but a slight tremor of a coarse sort and of "intention "type was noticed. The gait was fair, but although the arm-jerks were normal both ankle-jerks were absent and also the right knee-jerk. No other grossly abnormal physical signs were detected.

She was admitted to the Hull Royal Infirmary under my care on November 16,1936, and it was found that the Wassermann reaction of the blood was negative. The cerebrospinal fluid was not under pressure and was not abnormal in respect of its cell, protein, or glucose content. The Wassermann reaction of the fluid was also negative. Further clinical examination showed sluggishness of both biceps-jerks and, later, probable absence of the biceps- and supinator-jerks. Perimetry confirmed the constriction of the field of vision of the left eye, and ophthalmoscopy presented a confusing picture. The left optic disk seemed pale and the left retinal vessels were narrowed. The appearances were suggestive of secondary optic atrophy. The veins of the right retina were engorged and the right optic disk appeared to be affected by a mild papilloedema. These findings were confirmed by the ophthalmic surgeon (Dr. Stenhouse Stewart). A radiograph of the skull (Dr. J. E. Bannen) was reported upon as showing no abnormality. Apart from a suggestion of possible neuromyelitis optica no definite diagnosis could be formulated, and Mrs. A. left the Infirmary early in December, 1936. Later that month she consulted Dr. W. Russell Brain, who informed me that he considered her to be a casse of Adie's syndrome with tonic pupils and absent tendon-jerks.

The patient continued to attend my follow-up clinic, but her condition remained unchanged and no further symptoms were remarked upon until May, 1937. At this time both parotid glands began to swell. The enlargement was more pronounced on the left side than on the right, and it was not accompanied by pain, fever, or any constitutional disturbances. On June 19 the parotid swellings seemed quite unchanged. A degree of incoordination, as shown by finger-to-finger and finger-to-nose tests, was evident, but the other neurological findings, given above, were quite unaltered. A radiograph of the chest taken 